\title{
INTEGRATING EQUITY OBJECTIVES IN A ROAD NETWORK DESIGN MODEL
}

\author{
Bruno Santos \\ PhD Candidate (Transportation Engineering) \\ Department of Civil Engineering \\ University of Coimbra \\ Rua Luis Reis Santos - Polo II \\ 3030 - 290 Coimbra, Portugal \\ Phone: (+351) 239797131 \\ Fax: (+351) 239797142 \\ bsantos@dec.uc.pt

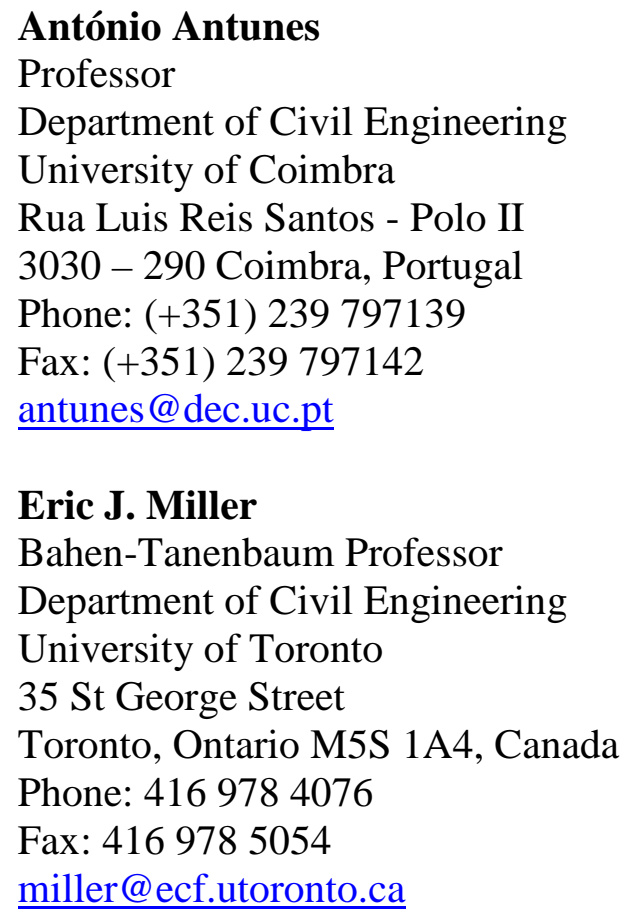

\begin{tabular}{|l|c|c|c|c|}
\hline & Abstract & Text & Pictures & Total \\
\hline Words & 190 & 4,851 & $6(\mathrm{x} 250)$ & $\mathbf{6 , 3 5 1}$ \\
\hline
\end{tabular}

Final Revised Paper for TRR Submission Date: March 31, 2008

$87^{\text {th }}$ Annual Meeting of Transportation Research Board, January 13-17, 2008, Washington D. C. on the topic Transportation Network Modeling (ADB30). 


\begin{abstract}
The traditional approach to the road network design problem focuses on the optimization of the network efficiency under a given budget. Generally, this leads to the improvement of roads next to the largest population centers, where travel demand is higher. Such implications are not consistent with sustainable development principles since this will tend to increase the dissimilarities between large and small centers' welfare. Notwithstanding this, equity issues were rarely taken into account in road network design. Moreover, all existing studies rely on a single equity measure. In this paper we propose a brief review of equity concerns in transportation planning and present a comparison of alternative equity measures. We selected three different equity measures and incorporated them into an accessibility-maximization road network design model. The three equity measures considered reflect different perspectives on equity: the accessibility to low-accessibility centers; the dispersion of accessibility values across all centers (Gini Coefficient); and the dispersion of accessibility values across all centers and across centers in the same region (Theil Index). The implications of adopting each one of these equity measures are illustrated through the application of the optimization model to three random networks.
\end{abstract}




\section{INTRODUCTION}

Most road network design approaches focus on improving the efficiency of a network by allocating a given budget to the construction of new roads and/or to the improvement of existing roads. The efficiency of the network is commonly assessed through generalized travel costs or aggregate accessibility measures. In both cases, the efficiency of the network is sensitive especially to improvements of links from and to the larger population centers of a network. These are, generally, the links with higher traffic flows in the network, for which a reduction in travel time can imply a significant reduction of generalized travel costs or aggregate accessibility values. Therefore, because of budgetary constraints, this type of approach usually leads to dense road networks next to the larger centers and to sparse road networks next to the smaller centers. A potential consequence of this will be the increase of regional disparities. This is certainly not the best solution for regions (or countries) looking for a well-balanced road network, capable of promoting regional cohesion (1).

Excessively uneven accessibility conditions in a region are not consistent with sustainable development principles (2). For this reason, equity issues should play an important role in road network design. Notwithstanding this, the integration of equity objectives in transportation planning is recent. Most of the initial studies including equity issues in transportation dealt with the fairness of transportation policies. Few studies in road network design took into account equity issues. Even for those few cases, the evaluation of equity relied on a single measure. In our opinion, it is necessary to consider alternative equity measures in road network design, and compare their implications.

In this paper we present a brief review of equity measures in transportation planning and present a comparison of alternative equity measures. We selected three different measures and incorporated them into an accessibility-maximization interurban road network design model. The three equity measures considered were: the accessibility to low-accessibility centers; the dispersion of accessibility values across all centers (Gini Coefficient); and the dispersion of accessibility values across all centers and across centers in the same region (Theil Index). The implications of adopting each one of these equity measures are illustrated through the application of the optimization model to three random networks.

The paper is organized as follows. In the next section, we introduce the equity issue and discuss the incorporation of equity into transportation planning. Then, we describe the formulation of the optimization model and present the equity measures. After that, we describe the results obtained through the model for the random networks. Finally, we provide some concluding remarks.

\section{EQUITY CONCEPTS}

"Equity" refers to the fairness and justice of the distribution of the impacts (benefits and costs) of an action on two or more units. Depending on the available data and the chosen equity (or inequality) measure, units can stand for individuals or groups. For the definition of groups, one can use collective units, such as households, disabled people, non-drivers, land-use type, or regions, and characteristics, such as income, travel cost, population, or age.

The concept of equity has been extensively used in different disciplines, e.g., geography $(3,4)$, medicine $(5,6)$, sociology $(7,8)$, economy $(9)$, and political sciences $(10)$. In the decisionmaking field, equity measures are commonly used to assess the economic and social impacts of different development scenarios. Despite the increasing effort to incorporate equity in decision- 
making models, there is little agreement about the best way to assess equity. A large number of measures can be found in the literature, but we are still far from a general consensus on the best measure(s) to use in each case. Still, few attempts have been made until now to assemble these measures, compare them, and define appropriate measure(s) for each type of application. One of the rare exceptions is Marsh and Shilling (11), where a detailed review of equity measures for public facility planning is presented.

In the transportation field, until the end of the nineties, equity issues were generally limited to the evaluation of the economic impacts of transportation policies. In most cases, these studies regarded distribution of policy impacts between different social groups in the case of the introduction of road prices in some links of the network $(12,13)$. It was only in 2002, when Meng and Yang (14) demonstrated that in the continuous network design problem the benefits of a capacity enhancement in some selected links can lead to an increase in travel costs for some (O-D) pairs, that the debate of equity issues in transportation network design became more intense. Yang and Zhang (12), also observed that for the congestion pricing problem there were significant differences between the benefits of some (O-D) pairs. Thus, in addition to the equity issues involving social groups they proposed the consideration of spatial equity in the road pricing problem.

After these studies, some other authors proposed the inclusion of equity concerns in network design problems. Antunes et al. (15) considered the distribution of accessibility gains across population centers in an accessibility-maximization model. Cheng and Yang (16) included spatial equity as a constraint in the link capacity improvement problem with demand uncertainty. More recently, Szeto and Lo (13) proposed the integration of equity in a time-step network design problem. They considered social and user equity for different periods of time.

All the measures used in the previous studies applied to equity across all individuals or groups regardless of their characteristics, needs or resources - that is, horizontal equity or egalitarianism. Another way of considering equity is by differentiating the impacts across individuals or groups that have different abilities or needs - that is, vertical equity or social inclusion. The concepts of horizontal and vertical equity were already present in equity studies in different disciplines when they were first introduced in the transportation field. Feng and $\mathrm{Wu}$ (17) made use of both concepts in a network design model. The aim was to have equitable accessibility across all the population centers of the study area (horizontal equity) and across the centers of the same region within the study area (vertical equity).

\section{DESIGN MODEL}

A considerable amount of research effort has been devoted to road network design models over the last forty years (see Yang and Bell (18) for a relatively recent review). Most of this effort was directed towards problems where the objective is to minimize the total network costs required to accommodate given traffic flows, assuming route choices to follow a user equilibrium pattern. In our opinion, this objective does not match the needs of long-term interurban road network design because of reasons that are thoroughly explained in Santos et al. (19). A better match would be achieved if the objective were to maximize the aggregate accessibility to population centers with a given budget. The match would be even better if other objectives were also taken into account. This is the case of the optimization model proposed in this paper, which includes an equity objective. The model can be formulated as follows: 
$\max Z=w_{A} \times \frac{A-A_{0}}{A_{B}-A_{0}}+w_{E} \times \frac{E-E_{0}}{E_{B}-E_{0}}$

subject to

$$
\begin{aligned}
& A=\sum_{j \in N} P_{j} \times A_{j}(\boldsymbol{y}) \\
& A_{j}(\boldsymbol{y})=\sum_{k \in N \backslash j} \frac{P_{k}}{C_{j k}(\boldsymbol{y})^{\beta}}, \forall j \in \boldsymbol{N} \\
& E=\eta(\boldsymbol{y}) \\
& \sum_{m \in M_{l}} y_{l m}=1, \forall l \in \boldsymbol{L} \\
& T_{l}(\boldsymbol{y}) \leq \sum_{m \in M_{l}} F_{m} \times y_{l m}, \forall l \in \boldsymbol{L} \\
& \sum_{l \in \boldsymbol{L}} \sum_{m \in M_{l}} e_{l m} \times y_{l m} \leq b \\
& T_{l} \geq 0, y_{l m} \in\{0,1\}, \forall l \in \boldsymbol{L}, m \in \boldsymbol{M}_{l}
\end{aligned}
$$

where $Z$ is the normalized value of a solution; $w_{A}$ and $w_{E}$ are the weights attached to accessibility and equity; $A$ and $E$ are the values of a solution in terms of each objective; $A_{B}$ and $A_{0}\left(E_{B}\right.$ and $\left.E_{0}\right)$ are reference maximum and minimum values for each objective; $N$ is the set of centers; $P_{j}$ is the population of center $j$; $A_{j}$ is the accessibility of center $j ; \boldsymbol{y}=\left\{y_{l m}\right\}$ is a matrix of binary variables equal to one if link $l$ is set at road type $m$ and equal to zero otherwise; $C_{j k}$ is the generalized cost for traveling between centers $j$ and $k ; \beta$ is an impedance parameter; $\eta$ is the equity measure; $\boldsymbol{M}_{l}$ is the set of possible road types for link $l ; \boldsymbol{L}$ is the set of links; $T_{l}$ is the estimated traffic flow in link $l ; F_{m}$ is the maximum service flow for a link of road type $m ; e_{l m}$ is the expenditure required to set link $l$ at road type $m$; and $b$ is the budget.

The (main) decision variables of this non-linear combinatorial optimization model are the $\boldsymbol{y}$ variables, which represent the road type to assign to the various links of the network. The objective-function [1] expresses the normalized value of model solutions considering both an accessibility objective and an equity objective. Weights are applied to the objectives to reflect their relative importance. Constraints [2] and [3] define the accessibility measure to be used, which is based on a widely-used measure proposed by Keeble (3). Constraint [2] defines aggregate accessibility and constraint [3] defines the accessibility of each center. Constraint [4] defines the equity measure as being dependent on the road type assigned to the various links of the network (several alternatives for the equity measure are presented below). Constraints [5] guarantee that each link will be set at one, and only one, road type. For some links, it may be undesirable to choose some road types because of environmental reasons. This is the reason why the set of road types $\left(\boldsymbol{M}_{l}\right)$ is indexed in the link. Constraints [6] ensure that the traffic flow estimated for each link will not exceed the maximum service flow consistent with the road type chosen for the link. Traffic flows on links are determined by assigning O/D traffic flows calculated with an unconstrained gravity model to the network assuming trips to be made through least-cost routes. Constraint [7] guarantees that the budget available for improving the network will not be exceeded. Expression [8] defines the domain for the decision variables. 


\section{EQUITY MEASURES}

Many equity measures have been proposed in the literature expressing different perceptions of fairness, but there is little agreement about the best measure(s) to apply in different situations. Besides this, different perspectives on equity can lead to different rankings of solutions and, ultimately, result in contradictions (20). Consequently, it is risky to assess equity based on a single measure without a comprehensive examination of several measures and their implications.

To the best of our knowledge, until now, all the studies that incorporated equity objectives in road network design relied on a single measure. There are no works reported in the literature comparing the application of alternative equity measures. In this paper we selected three of these measures for comparison within the optimization model presented before. We used an absolute concern with equity, since network improvements are aimed at an equitable distribution of accessibility across all nodes. A possible option would involve the distribution of accessibility gains, therefore a relative concern with equity.

\section{Accessibility of low-accessibility centers}

In road network design, when the only objective is the maximization of accessibility, one can end up with a solution where the largest accessibility gains occur in the most developed areas. The difference between centers with higher accessibility and centers with lower accessibility will tend to increase. One natural way of decreasing the disparities between centers is to increase the accessibility of the centers that have lower accessibility, rather than those with higher accessibility. In order to represent this idea we selected the accessibility of a given percentage of centers with lower accessibility as an equity measure (14):

$$
\eta(\boldsymbol{y})=\sum_{j \in N_{P_{\varepsilon}}} P_{j} \times A_{j}(\boldsymbol{y})
$$

where $N_{P_{\varepsilon}}$ is the set of $\varepsilon$-percent centers with lower accessibility.

This is a simple vertical equity measure. Centers with lower accessibility are favored in relation to other centers.

\section{Gini Coefficient}

In a perfect, fully-equitable region, all centers would have exactly the same accessibility. A good way to measure the inequality of a situation is to compare it with a perfect region. To do this, we can resort to the Gini Coefficient or Gini Index, one of the most widely used measures of inequality. For the application of this measure in this study we used the following formulation:

$$
\eta(\boldsymbol{y})=\frac{\sum_{j \in N} \sum_{k \in N}\left|A_{j}(\boldsymbol{y})-A_{k}(\boldsymbol{y})\right|}{2 n^{2} \bar{A}}
$$

where $n$ is the number of centers that belong to $N$, and $\bar{A}$ is the average accessibility to centers that belong to $N$.

The Gini Coefficient can be defined as a measure of dispersion scaled by twice the value of the mean. In practice, it measures the relative difference between what we have and what 
would be a perfect situation. The value of the coefficient belongs to the interval $[0,1]$ and the lower the value is, the closer it is to the perfect situation.

This measure is a horizontal equity measure since every center is treated in the same way.

\section{Theil Index}

In some situations, minimizing inequalities between individuals or groups can be as important as minimizing inequalities within groups. For instance, when considering a country divided into regions, we should aim at minimizing the inequalities existing in those regions and, at the same time, the inequalities between the different regions of the country. In order to represent this idea we selected the Theil (Inequality) Index (21):

$$
\begin{aligned}
& \eta(\boldsymbol{y})=\sum_{g \in \boldsymbol{G}} \hat{A}_{g} \cdot T_{g}+\sum_{g \in \boldsymbol{G}} \hat{A}_{g} \cdot \ln \left(\frac{\overline{A_{g}}}{\bar{A}}\right) \\
& \text { with } \quad \hat{A}_{g}=\frac{\sum_{j \in N_{\boldsymbol{G}}} A_{j}}{\sum_{j \in N} A_{j}}=\frac{n_{g} \times \bar{A}_{g}}{n \times \bar{A}} \\
& T_{g}=\frac{1}{N} \sum_{j \in N}\left(\frac{A_{j}}{\bar{A}}\right) \times \ln \left(\frac{A_{j}}{\bar{A}}\right)
\end{aligned}
$$

where $\boldsymbol{G}$ is the set of groups (e.g. regions), $\hat{A}_{g}$ is the weight of group $g \in \boldsymbol{G}$ in the accessibility to all centers, $T_{g}$ is the Theil Index of group $g, \overline{A_{g}}$ is the average accessibility to centers of group $g$, $\bar{A}$ is the average accessibility to all centers, $N_{g}$ is the set of centers that belong to region $g$, and $n_{g}$ is the number of centers that belong to region $g$.

Expression [11] defines the Theil Index of the region, considering the inequality within each sub-region (first term) and the inequality across the sub-regions (second term). Expression [12] defines the share of accessibility to the centers of a region when related to the accessibility to all centers and expression [13] defines the Theil Index of each region.

Due to its decomposability properties, the Theil Index is a popular measure, used for example to assess income dispersion across regions. The Theil Index takes values between zero (perfect equality) and $\ln (n)$ (maximum inequality) and, as it happens with the Gini coefficient, it measures the difference between a perfect situation and the actual situation. However, in contrast with the other measures selected, the Theil Index lacks an appealing interpretation.

This measure is, simultaneously, a horizontal and a vertical equity measure since it considers both concepts of equity - horizontal as it deals with all the centers in the same way, and vertical as it deals with centers according to the region they belong to.

\section{MODEL APPLICATIONS}

In order to compare the results that one can obtain when using the different equity measures, we applied the optimization model to three random road networks defined for a territory with the shape of a square with sides equal to $100 \mathrm{~km}$ and a given number of centers (cities) with population following a Zipf distribution. The three networks are depicted in Figure 1 (and described in detail in Appendixes A and B). They consist of two networks of 10 population centers and one network of 20 population centers. The centers are connected by links. In 
addition, some additional, pre-defined links can be built in the future. The centers were named according to their population ranking: center 1 is the largest center; center 2 is the secondlargest; and so forth. The territory is divided into four regions, each one corresponding to a quadrant of the plane - northeast, northwest, southwest and southeast. Most existing roads are slow two-lane highways (free-flow speed equal to $70 \mathrm{~km} / \mathrm{h}$ ). Other road types are fast two-lane highway $(90 \mathrm{~km} / \mathrm{h})$, and four-lane freeway $(120 \mathrm{~km} / \mathrm{h})$. Detailed information about centers and links of the three networks can be found in Table 1 and Table 2. The costs per kilometer for road construction and upgrading are presented in Table 3. The budget available for the improvement of each network was set equal to 25 percent of the total expenditure involved in upgrading all links to a three-lane freeway. The networks were generated through the procedure described in Santos et al (22). We used small networks for these exercises because this makes the results obtained through the model easier to understand and discuss.

For solving the model, we used the enhanced genetic algorithm previously developed for the same model without the equity objective (22). When applied to large networks (with up to 200 links), this algorithm has been shown to give excellent solutions as compared to classic local search and genetic algorithms within acceptable computing effort (eight hours). When applied to small networks (up to twenty links), for which we were able to find optimum solutions through complete enumeration only after several hours, it was always able to identify optimum solutions in a few seconds.

The model was first applied to the networks considering only the accessibilitymaximization objective. Then, the equity objective was added to the model, considering separately the three measures introduced above. Both objectives were given the same weight (50/100).

\section{Maximization of accessibility}

When only the accessibility-maximization objective is considered, the optimum solution consists mainly of improving links connecting large centers, with the remaining budget being assigned to the upgrade of links connecting either large centers to neighboring small centers or two neighboring small centers with each other (Figure 2a). For all the three networks, the five largest centers are connected with each other by four-lane freeways. The budgetary constraint prevents the upgrade of other links, resulting in a low accessibility to centers located far away from the larger centers. This is the case of Centers 6 and 7 in Network 1, Centers 8 and 10 in Network 2, and Centers 15, 18, and 20 in Network 3.

As we could expect, the average accessibility obtained when only the accessibilitymaximization objective is considered is always higher than the accessibility obtained when equity objectives are added (Table 4). It is also for that objective that the largest accessibility gap occurs (by accessibility gap we mean the difference between the highest and the lowest accessibility values obtained for the centers of a region). In addition, when we compare the average accessibility for the four regions of each network, the highest standard deviation occurs when only the accessibility-maximization objective is considered.

The solutions obtained with only the accessibility-maximization objective will be used as reference solutions from this point forward.

\section{Maximization of accessibility to low-accessibility centers}

When we introduce equity concerns in the road network model, the results change considerably. In the case of considering the accessibility of the 20-percent centers with lower accessibility, the 
optimum solutions involve, in most cases, the upgrade of links connecting centers with poor accessibility that have either large centers close to them or small centers very close to them (Figure 2b). That is, we obtain optimum solutions for which the accessibility gap is clearly smaller. For example, in Network 1, the two centers with lower accessibility were Center 6 and Center 7. These centers are now connected with each other by a freeway and connected to other centers by a fast two-lane highway. Their accessibility (the accessibility of the NE region) increased by 15.5 percent. Because of the budget constraint, there are fewer freeways in the south when compared to the reference solution. In Network 2, Centers 4 and 8 were the centers with lower accessibility. Center 4 was already in the reference solution connected to the largest centers by freeway. Little was still to do in order to increase its accessibility. However, the accessibility of Center 8 is now increased by 20.2 percent by connecting this center to the nearby Center 5 by freeway and by building a new road between Center 5 and Center 1 . In Network 3, the four centers with lower accessibility were Center 15, Center 18, Center 20, and the peripheral Center 1 . The solution to increase the accessibility to these nodes was the construction of a freeway connecting all these nodes. This freeway starts at Center 1, passes through Centers 2, 15, 18, and 20, and ends at Center 4. The cost of this new freeway corridor prevents the existence of other freeways in the SW region that existed in the reference solution.

As we could expect, for all the three networks, the accessibility of the 20-percent centers with lower accessibility is always higher when we include this equity measure.

\section{Gini Coefficient minimization}

When the Gini Coefficient is included as the equity measure, the optimum solutions generally involve the upgrade of links that increase the accessibility to centers with accessibility lower than average to the detriment of the links connecting centers with good accessibility (Figure 2c). For example, in Network 1, the accessibility to Centers 6 and 7, NE region, is improved by 14.0 percent while the accessibility of the SW region decreases by 10.0 percent. In Network 2, the disparity between south and north is diminished. For example, the accessibility of the SE region increases by 13.3 percent, while the accessibility of the NW and NE regions decreases by 13.1 and 14.7 percent, respectively. In Network 3, to increase the accessibility to low-accessibility centers, such as Centers 1,7,15, and 18, there is a decrease in the accessibility to the nodes of the SW region. The accessibility to Centers $1,7,15$, and 18, increases by $3.1,13.5,17.3$, and 18.9 percent, respectively. The accessibility of the SW Region decreases by 11.1 percent.

With the inclusion of the Gini Coefficient as the equity measure the accessibility gap decreases considerably for all three networks - 19.3 percent for Network 1, 31.4 percent for Network 2, and 14.8 for Network 3.

\section{Theil Index minimization}

When the Theil Index is included as the equity measure, the optimum solution reflects the concern of minimizing the differences of accessibility within the region and the differences of accessibility within each of the four regions. In general, the regions will be more homogenous, with a more balanced distribution of fast connections across all regions (Figure $2 \mathrm{~d}$ ). In Network 1, the lower average accessibility occurred for NE region, but with the incorporation of the Theil Index the average accessibility of that region increases by 12.6 percent. For the SE region, where the average accessibility was also low, the average accessibility does not increase but is not as penalized as it was in the solutions obtained for the other equity measures. In Network 2, the SE region is favored in relation to the other regions. The average accessibility of this region 
increases by 11.8 percent. In Network 3, the NE region is the favored region with an average accessibility increase of 3.5 percent. In this larger network it is possible to verify that when the Theil Index is considered as the equity measure we obtain a more balanced distribution of freeways across the four regions.

For Network 1 and Network 2, the values of the standard deviation are much lower for this equity measure than for the other measures. This means that there is more of a balance between the four regions. For Network 3, the standard deviation is slightly higher when maximizing for the Theil Index than when maximizing for the Gini Coefficient, even though the Theil Index is lower (12.5 percent). The reason for this is because the accessibility to centers within each region is more equitable in this case.

\section{CONCLUSION}

In this paper, we presented a brief review of equity concerns in transportation planning. Many equity measures have been proposed in the literature, expressing different perceptions of fairness. However, there is little consensus about the appropriate measure(s) to apply in different situations. For this study, we selected three different equity measures. We provided a comparison of these measures by incorporating them in an accessibility-maximization road network design model and applying the model to three random networks. We verified that, depending on the equity measure used, we can have considerably different results, reflecting different concepts of equity. As a result, for the best evaluation of equity it is imperative to have a good knowledge of the problem as well as of the issues involved (social, economic, environmental, etc.). Furthermore, for a comprehensive consideration of equity concerns in road network design, the incorporation of more than one equity measure in the optimization model can be necessary. The inclusion of different equity perceptions can result in a conflict of interests but can provide a more consistent analysis of equity. Hence, the incorporation of more than one equity objective in the optimization model used in this paper can be an interesting extension to this work.

\section{ACKNOWLEDGMENTS}

The participation of the first author in the study reported in this article has been supported by Fundação para a Ciência e Tecnologia through grant SFRH/BD/16407/2004. 


\section{REFERENCES}

1. Fernandes, C. and J. Viegas. Private Financing of Road Infrastructure: The Portuguese Experience. In Transportation Research Record: Journal of the Transportation Research Board, No. 1659, Transportation Research Board of the National Academies, Washington, D.C., 1999, pp. 23-30.

2. Gudmundsson, H. and M. Höjer, M. Sustainable Development Principles and Their Implications for Transport, Ecological Economics, Vol. 19, No. 3, 1996, pp. 269-282.

3. Keeble, D., P. L. Owens, and C. Thompson. Regional Accessibility and Economic-Potential in the European-Community. Regional Studies, Vol. 16, No. 6, 1982, pp. 419-431.

4. Truelove, M. Measurement of Spatial Equity. Environment and Planning C - Government and Policy, Vol. 11, No. 1, 1993, pp. 19-34.

5. Bloom, G. Equity in Health in Unequal Societies: Meeting Health Needs in Contexts of Social Change. Health Policy, Vol. 57, No. 3, 2001, pp. 205-224.

6. Rosero-Bixby, L. Spatial Access to Health Care in Costa Rica and its Equity: a GIS-based Study. Social Science and Medicine, Vol. 58, No. 7, 2004, pp. 1271-1284.

7. Kokko, H., A. Mackenzie, J. D. Reynolds, J. Lindström, and W. J Sutherland. Measures of Inequality Are Not Equal. The American Naturalist, Vol. 154, No. 3, 1999, pp. 358 - 382.

8. Frederickson, H. G. Public-Administration and Social Equity. Public Administration Review, Vol. 50, No. 2, 1990, pp. 228-237.

9. Atkinson, A. B. Income Inequality in the UK. Health Economics, Vol. 8, No. 4, 1999, pp. 283-288.

10. Maniquet, F. and Sprumont, Y. Welfare Egalitarianism in Non-Rival Environments. Journal of Economic Theory, Vol. 120, No. 2, 2005, pp. 155-174.

11. Marsh, M. T. and D. Schilling. A. Equity Measurement in Facility Location Analysis - a Review and Framework. European Journal of Operational Research, Vol. 74, No. 1, 1994, pp. 1-17.

12. Yang, H. and X. N. Zhang. Multiclass Network Toll Design Problem with Social and Spatial Equity Constraints. Journal of Transportation Engineering-ASCE, Vol. 128, No. 5, 2002, pp. 420-428.

13. Szeto, W. Y. and H. K. Lo. Transportation Network Improvement and Tolling Strategies: The Issue of Intergeneration Equity. Transportation Research Part A: Policy and Practice, Vol. 40, No. 3, 2006, pp. 227-243.

14. Meng, Q. and H. Yang, Benefit Distribution and Equity in Road Network Design. Transportation Research Part B-Methodological, Vol. 36, No. 1, 2002, pp. 19-35.

15. Antunes, A., A. Seco, and N. Pinto. An Accessibility-Maximization Approach to Road Network Planning. Computer-Aided Civil and Infrastructure Engineering, Vol. 18, No. 3, 2003, pp. 224-240.

16. Chen, A. and C Yang. Stochastic Transportation Network Design Problem with Spatial Equity Constraint. In Transportation Research Record: Journal of the Transportation Research Board, No. 1882, Transportation Research Board of the National Academies, Washington, D.C., 2004, pp. 97-104.

17. Feng, C. M. and J. Y. J. Wu. Highway Investment Network Design Model for Equity Issues. Journal of Urban Planning and Development-ASCE, Vol. 129, No. 3, 2003, pp. 161-176.

18. Yang, H. and Bell, M. G. H. Models and Algorithms for Road Network Design: a Review and Some New Developments. Transport Reviews, Vol. 18, No. 3, 1998, pp. 257-278. 
19. Santos, B., Antunes, A. and Miller, E. A Multi-Objective Approach to Road Network Planning. Presented at the $11^{\text {th }}$ World Conference on Transportation Research, Berkeley, CA, 2007.

20. Ramjerdi, F. Equity Measures and Their Performance in Transportation. In Transportation Research Record: Journal of the Transportation Research Board, No. 1983, Transportation Research Board of the National Academies, Washington, D.C., 2006, pp. 67-74.

21. Theil, H. Foundations of Economic Justice. Chicago, IL, USA, 1967.

22. Santos, B., Antunes, A. and Miller, E. J. Solving an Accessibility-Maximization Road Network Design Model: a Comparison of Heuristics. Advanced OR and AI Methods in Transportation, Poznan, Poland, 2005, pp. 692-697. 


\section{TABLES AND FIGURES}

TABLE 1 - Node data

TABLE 2 - Link data

TABLE 3 - Road construction and upgrading costs per kilometer

TABLE 4 - Summary of results for the random networks

FIGURE 1 - Random networks

FIGURE 2 - Results for the random networks 
TABLE 1 - Node data

\begin{tabular}{|c|c|c|c|c|c|}
\hline \multirow{2}{*}{ Network } & \multirow{2}{*}{ Center } & \multicolumn{2}{|c|}{ Coordinates } & \multirow{2}{*}{ Region } & \multirow{2}{*}{$\begin{array}{l}\text { Population } \\
\left(\times 10^{3} \text { inh. }\right)\end{array}$} \\
\hline & & $\mathrm{X}$ & $\mathrm{Y}$ & & \\
\hline \multirow{10}{*}{1} & Center 1 & 637 & 46 & $\mathrm{SE}$ & 687 \\
\hline & Center 2 & 362 & 874 & NW & 352 \\
\hline & Center 3 & 396 & 414 & SW & 237 \\
\hline & Center 4 & 63 & 299 & SW & 195 \\
\hline & Center 5 & 327 & 311 & SW & 148 \\
\hline & Center 6 & 936 & 748 & $\mathrm{NE}$ & 117 \\
\hline & Center 7 & 833 & 1000 & $\mathrm{NE}$ & 105 \\
\hline & Center 8 & 258 & 0 & SW & 86 \\
\hline & Center 9 & 178 & 1000 & NW & 78 \\
\hline & Center 10 & 477 & 230 & SW & 69 \\
\hline \multirow{10}{*}{2} & Center 1 & 209 & 560 & NW & 669 \\
\hline & Center 2 & 252 & 269 & SW & 408 \\
\hline & Center 3 & 102 & 807 & NW & 250 \\
\hline & Center 4 & 747 & 936 & NE & 183 \\
\hline & Center 5 & 618 & 280 & SE & 144 \\
\hline & Center 6 & 424 & 699 & NW & 120 \\
\hline & Center 7 & 80 & 1000 & NW & 102 \\
\hline & Center 8 & 951 & 0 & SE & 86 \\
\hline & Center 9 & 48 & 635 & NW & 75 \\
\hline & Center 10 & 607 & 22 & SE & 70 \\
\hline \multirow{20}{*}{3} & Center 1 & 120 & 869 & NW & 1028 \\
\hline & Center 2 & 472 & 693 & NW & 519 \\
\hline & Center 3 & 43 & 198 & SW & 399 \\
\hline & Center 4 & 747 & 154 & SE & 258 \\
\hline & Center 5 & 307 & 165 & SW & 226 \\
\hline & Center 6 & 824 & 242 & SE & 183 \\
\hline & Center 7 & 659 & 946 & $\mathrm{NE}$ & 148 \\
\hline & Center 8 & 0 & 484 & SW & 137 \\
\hline & Center 9 & 10 & 44 & SW & 115 \\
\hline & Center 10 & 637 & 748 & $\mathrm{NE}$ & 104 \\
\hline & Center 11 & 285 & 143 & SW & 98 \\
\hline & Center 12 & 384 & 759 & NW & 89 \\
\hline & Center 13 & 329 & 176 & SW & 81 \\
\hline & Center 14 & 505 & 957 & $\mathrm{NE}$ & 75 \\
\hline & Center 15 & 945 & 770 & $\mathrm{NE}$ & 69 \\
\hline & Center 16 & 505 & 616 & $\mathrm{NE}$ & 65 \\
\hline & Center 17 & 208 & 55 & SW & 61 \\
\hline & Center 18 & 1000 & 682 & $\mathrm{NE}$ & 58 \\
\hline & Center 19 & 615 & 297 & SE & 54 \\
\hline & Center 20 & 978 & 385 & SE & 52 \\
\hline
\end{tabular}


TABLE 2 - Link data

\begin{tabular}{|c|c|c|c|c|c|c|c|c|c|}
\hline \multirow{2}{*}{ Network } & \multirow{2}{*}{ Link } & \multirow{2}{*}{$\begin{array}{c}\text { Start } \\
\text { Center }\end{array}$} & \multirow{2}{*}{$\begin{array}{l}\text { End } \\
\text { Center }\end{array}$} & \multirow{2}{*}{$\begin{array}{c}\text { Length } \\
(\mathrm{km})\end{array}$} & \multicolumn{5}{|c|}{ Solution } \\
\hline & & & & & 0 & 1 & 2 & 3 & 4 \\
\hline \multirow{16}{*}{1} & Link 1 & 1 & 10 & 21.3 & Slow 2-lane & 4-lane freeway & 4-lane freeway & Fast 2-lane & 4-lane freeway \\
\hline & Link 2 & 1 & 8 & 33.2 & Slow 2-lane & Slow 2-lane & Slow 2-lane & Slow 2-lane & 4-lane freeway \\
\hline & Link 3 & 8 & 10 & 27.6 & Slow 2-lane & Slow 2-lane & Slow 2-lane & Slow 2-lane & Slow 2-lane \\
\hline & Link 4 & 2 & 3 & 40.1 & Slow 2-lane & 4-lane freeway & Fast 2-lane & 4-lane freeway & Fast 2-lane \\
\hline & Link 5 & 2 & 4 & 56.4 & Project Road & Project Road & Project Road & Project Road & Project Road \\
\hline & Link 6 & 2 & 6 & 51.2 & Project Road & Project Road & Project Road & Project Road & Project Road \\
\hline & Link 7 & 3 & 6 & 55.2 & Slow 2-lane & Slow 2-lane & Fast 2-lane & Slow 2-lane & Slow 2-lane \\
\hline & Link 8 & 2 & 9 & 19.4 & Slow 2-lane & 4-lane freeway & Slow 2-lane & 4-lane freeway & Slow 2-lane \\
\hline & Link 9 & 2 & 7 & 42.5 & Slow 2-lane & Slow 2-lane & Fast 2-lane & 4-lane freeway & 4-lane freeway \\
\hline & Link 10 & 6 & 7 & 23.8 & Slow 2-lane & Fast 2-lane & 4-lane freeway & 4-lane freeway & 4-lane freeway \\
\hline & Link 11 & 3 & 5 & 10.8 & Slow 2-lane & 4-lane freeway & 4-lane freeway & Fast 2-lane & Slow 2-lane \\
\hline & Link 12 & 4 & 5 & 23.0 & Slow 2-lane & 4-lane freeway & Fast 2-lane & 4-lane freeway & 4-lane freeway \\
\hline & Link 13 & 3 & 10 & 17.5 & Slow 2-lane & 4-lane freeway & 4-lane freeway & Fast 2-lane & Fast 2-lane \\
\hline & Link 14 & 5 & 10 & 14.8 & Slow 2-lane & 4-lane freeway & Fast 2-lane & Slow 2-lane & Slow 2-lane \\
\hline & Link 15 & 4 & 8 & 31.1 & Slow 2-lane & Slow 2-lane & Slow 2-lane & Slow 2-lane & Slow 2-lane \\
\hline & Link 16 & 5 & 8 & 27.7 & Slow 2-lane & Fast 2-lane & Slow 2-lane & Slow 2-lane & Slow 2-lane \\
\hline & Link 1 & 1 & 2 & 27.3 & Fast 2-lane & 4-lane freeway & 4-lane freeway & 4-lane freeway & Fast 2-lane \\
\hline & Link 2 & 1 & 5 & 46.0 & Project Road & Project Road & Fast 2-lane & Project Road & 4-lane freeway \\
\hline & Link 3 & 2 & 5 & 34.0 & Slow 2-lane & 4-lane freeway & Slow 2-lane & 4-lane freeway & Slow 2-lane \\
\hline & Link 4 & 1 & 9 & 16.6 & Slow 2-lane & 4-lane freeway & Fast 2-lane & Slow 2-lane & Slow 2-lane \\
\hline & Link 5 & 1 & 3 & 25.1 & Project Road & 4-lane freeway & 4-lane freeway & 4-lane freeway & 4-lane freeway \\
\hline & Link 6 & 1 & 6 & 23.9 & Slow 2-lane & 4-lane freeway & 4-lane freeway & Slow 2-lane & Fast 2-lane \\
\hline & Link 7 & 3 & 6 & 31.6 & Slow 2-lane & Fast 2-lane & Slow 2-lane & Slow 2-lane & Slow 2-lane \\
\hline & Link 8 & 3 & 9 & 16.8 & Slow 2-lane & Fast 2-lane & Slow 2-lane & Slow 2-lane & Slow 2-lane \\
\hline 2 & Link 9 & 5 & 6 & 43.0 & Slow 2-lane & Slow 2-lane & Slow 2-lane & Slow 2-lane & Slow 2-lane \\
\hline & Link 10 & 2 & 10 & 40.2 & Slow 2-lane & Slow 2-lane & Slow 2-lane & 4-lane freeway & Slow 2-lane \\
\hline & Link 11 & 5 & 10 & 24.0 & Slow 2-lane & Slow 2-lane & Slow 2-lane & 4-lane freeway & Fast 2-lane \\
\hline & Link 12 & 3 & 7 & 18.1 & Slow 2-lane & 4-lane freeway & Fast 2-lane & 4-lane freeway & 4-lane freeway \\
\hline & Link 13 & 4 & 5 & 62.2 & Project Road & Project Road & Project Road & Project Road & Project Road \\
\hline & Link 14 & 4 & 6 & 37.2 & Slow 2-lane & 4-lane freeway & 4-lane freeway & Fast 2-lane & 4-lane freeway \\
\hline & Link 15 & 5 & 8 & 40.5 & Slow 2-lane & Slow 2-lane & 4-lane freeway & Slow 2-lane & 4-lane freeway \\
\hline & Link 16 & 4 & 7 & 62.3 & Project Road & Project Road & Project Road & Project Road & Project Road \\
\hline & Link 17 & 8 & 10 & 32.1 & Slow 2-lane & Slow 2-lane & Slow 2-lane & Fast 2-lane & Slow 2-lane \\
\hline & Link 1 & 1 & 8 & 36.7 & Slow 2-lane & 4-lane freeway & 4-lane freeway & 4-lane freeway & 4-lane freeway \\
\hline & Link 2 & 1 & 12 & 26.0 & Fast 2-lane & 4-lane freeway & 4-lane freeway & 4-lane freeway & 4-lane freeway \\
\hline & Link 3 & 8 & 12 & 43.0 & Slow 2-lane & Slow 2-lane & Slow 2-lane & Slow 2-lane & Slow 2-lane \\
\hline & Link 4 & 1 & 14 & 35.9 & Project Road & Project Road & Project Road & 4-lane freeway & Fast 2-lane \\
\hline & Link 5 & 12 & 14 & 21.1 & Slow 2-lane & Fast 2-lane & Slow 2-lane & Slow 2-lane & Slow 2-lane \\
\hline & Link 6 & 2 & 10 & 15.8 & Slow 2-lane & 4-lane freeway & 4-lane freeway & 4-lane freeway & 4-lane freeway \\
\hline & Link 7 & 2 & 14 & 24.2 & Project Road & Project Road & Project Road & Project Road & Slow 2-lane \\
\hline & Link 8 & 10 & 14 & 22.5 & Slow 2-lane & Slow 2-lane & Slow 2-lane & Slow 2-lane & Slow 2-lane \\
\hline & Link 9 & 2 & 16 & 7.6 & Slow 2-lane & 4-lane freeway & 4-lane freeway & Fast 2-lane & Fast 2-lane \\
\hline & Link 10 & 10 & 16 & 17.0 & Slow 2-lane & Slow 2-lane & Slow 2-lane & Slow 2-lane & Slow 2-lane \\
\hline & Link 11 & 2 & 12 & 10.0 & Slow 2-lane & 4-lane freeway & 4-lane freeway & 4-lane freeway & Fast 2-lane \\
\hline & Link 12 & 3 & 8 & 26.3 & Fast 2-lane & Fast 2-lane & Fast 2-lane & 4-lane freeway & Fast 2-lane \\
\hline & Link 13 & 5 & 8 & 40.3 & Project Road & Project Road & Project Road & Project Road & Project Road \\
\hline & Link 14 & 3 & 11 & 22.6 & Slow 2-lane & 4-lane freeway & 4-lane freeway & Slow 2-lane & Fast 2-lane \\
\hline & Link 15 & 5 & 11 & 2.8 & Slow 2-lane & 4-lane freeway & 4-lane freeway & Fast 2-lane & Fast 2-lane \\
\hline & Link 16 & 3 & 9 & 14.3 & Slow 2-lane & 4-lane freeway & Slow 2-lane & 4-lane freeway & 4-lane freeway \\
\hline & Link 17 & 3 & 17 & 19.8 & Slow 2-lane & Slow 2-lane & Slow 2-lane & Slow 2-lane & Slow 2-lane \\
\hline 3 & Link 18 & 9 & 17 & 18.0 & Slow 2-lane & Slow 2-lane & Slow 2-lane & Slow 2-lane & Slow 2-lane \\
\hline & Link 19 & 11 & 17 & 10.6 & Slow 2-lane & 4-lane freeway & Slow 2-lane & Slow 2-lane & 4-lane freeway \\
\hline & Link 20 & 4 & 6 & 10.6 & Slow 2-lane & 4-lane freeway & 4-lane freeway & 4-lane freeway & 4-lane freeway \\
\hline & Link 21 & 4 & 19 & 17.7 & Slow 2-lane & 4-lane freeway & Slow 2-lane & 4-lane freeway & 4-lane freeway \\
\hline & Link 22 & 6 & 19 & 19.6 & Slow 2-lane & Fast 2-lane & Fast 2-lane & Slow 2-lane & Slow 2-lane \\
\hline & Link 23 & 6 & 20 & 19.1 & Slow 2-lane & Slow 2-lane & 4-lane freeway & 4-lane freeway & 4-lane freeway \\
\hline & Link 24 & 13 & 19 & 28.2 & Slow 2-lane & Fast 2-lane & Fast 2-lane & Slow 2-lane & Slow 2-lane \\
\hline & Link 25 & 5 & 13 & 2.2 & Fast 2-lane & 4-lane freeway & 4-lane freeway & Fast 2-lane & Fast 2-lane \\
\hline & Link 26 & 7 & 10 & 18.1 & Slow 2-lane & Slow 2-lane & 4-lane freeway & Slow 2-lane & 4-lane freeway \\
\hline & Link 27 & 7 & 14 & 14.0 & Slow 2-lane & Slow 2-lane & Slow 2-lane & 4-lane freeway & 4-lane freeway \\
\hline & Link 28 & 7 & 15 & 30.5 & Slow 2-lane & Slow 2-lane & Slow 2-lane & Slow 2-lane & Slow 2-lane \\
\hline & Link 29 & 10 & 15 & 28.1 & Slow 2-lane & Slow 2-lane & 4-lane freeway & 4-lane freeway & Fast 2-lane \\
\hline & Link 30 & 8 & 16 & 47.5 & Project Road & Project Road & Project Road & Project Road & Project Road \\
\hline & Link 31 & 13 & 16 & 43.1 & Slow 2-lane & 4-lane freeway & Slow 2-lane & Slow 2-lane & Slow 2-lane \\
\hline & Link 32 & 15 & 18 & 9.4 & Slow 2-lane & Slow 2-lane & 4-lane freeway & 4-lane freeway & 4-lane freeway \\
\hline & Link 33 & 16 & 19 & 30.7 & Slow 2-lane & 4-lane freeway & Slow 2-lane & Fast 2-lane & Fast 2-lane \\
\hline & Link 34 & 10 & 20 & 45.3 & Slow 2-lane & Slow 2-lane & Fast 2-lane & Slow 2-lane & Slow 2-lane \\
\hline & Link 35 & 18 & 20 & 27.1 & Slow 2-lane & Slow 2-lane & 4-lane freeway & Slow 2-lane & Slow 2-lane \\
\hline & 0 & Initial & & & & & & & \\
\hline & 1 & Maximiza & acces & & & & & & \\
\hline & 2 & Maximizat & access & and $m$ & ation of acess & to low-accessi & centers & & \\
\hline & 3 & Maximizat & access & ne & ation of Gini & icient & & & \\
\hline & 4 & Maximizat & f accessi & and $\mathrm{m}$ & ation of Theil & & & & \\
\hline
\end{tabular}


TABLE 3 - Road construction and upgrading costs per kilometer

\begin{tabular}{lccc}
\hline \multirow{2}{*}{ From } & \multicolumn{3}{c}{ To } \\
\cline { 2 - 4 } & $\begin{array}{c}\text { Slow two-lane } \\
\text { highway }\end{array}$ & $\begin{array}{c}\text { Fast two-lane } \\
\text { highway }\end{array}$ & $\begin{array}{c}\text { Four-lane } \\
\text { freeway }\end{array}$ \\
\hline Possible road & 1 & 2 & 3 \\
Slow two-lane highway & - & 1.5 & 2.5 \\
Fast two-lane highway & - & - & 2 \\
\hline
\end{tabular}


TABLE 4 - Summary of results for the random networks

\begin{tabular}{|c|c|c|c|c|c|c|c|c|c|c|}
\hline \multirow{2}{*}{ Network } & \multirow{2}{*}{ Solution } & \multicolumn{3}{|c|}{ Accessibility of centers } & \multirow{2}{*}{$\begin{array}{l}\text { Accessibility to low- } \\
\text { accessibility centers }\end{array}$} & \multicolumn{5}{|c|}{ Average accessibility of sub-regions } \\
\hline & & Highest & Lowest & Average & & NE & NW & SW & SE & Std.Dev. \\
\hline \multirow{5}{*}{1} & 0 & 1.199 & 0.363 & 0.648 & 0.727 & 0.363 & 0.478 & 0.885 & 0.368 & 0.183 \\
\hline & 1 & 1.640 & 0.404 & 0.846 & 0.811 & 0.406 & 0.650 & 1.172 & 0.491 & 0.298 \\
\hline & 2 & 1.594 & 0.468 & 0.812 & 0.937 & 0.469 & 0.546 & 1.122 & 0.480 & 0.272 \\
\hline & 3 & 1.431 & 0.433 & 0.796 & 0.874 & 0.463 & 0.655 & 1.056 & 0.441 & 0.247 \\
\hline & 4 & 1.504 & 0.432 & 0.775 & 0.907 & 0.457 & 0.545 & 0.924 & 0.475 & 0.190 \\
\hline \multirow{5}{*}{2} & 0 & 1.277 & 0.304 & 0.657 & 0.654 & 0.350 & 0.827 & 0.734 & 0.449 & 0.154 \\
\hline & 1 & 1.700 & 0.326 & 0.867 & 0.794 & 0.468 & 1.161 & 0.881 & 0.505 & 0.285 \\
\hline & 2 & 1.513 & 0.392 & 0.838 & 0.853 & 0.461 & 1.095 & 0.854 & 0.529 & 0.255 \\
\hline & 3 & 1.306 & 0.364 & 0.804 & 0.763 & 0.399 & 1.009 & 0.878 & 0.572 & 0.242 \\
\hline & 4 & 1.315 & 0.402 & 0.811 & 0.848 & 0.446 & 1.039 & 0.777 & 0.565 & 0.226 \\
\hline \multirow{5}{*}{3} & 0 & 5.163 & 0.739 & 1.705 & 3.328 & 1.343 & 1.538 & 2.439 & 1.089 & 1.035 \\
\hline & 1 & 5.975 & 0.878 & 2.108 & 3.682 & 1.618 & 1.989 & 3.013 & 1.476 & 0.601 \\
\hline & 2 & 5.851 & 0.887 & 2.057 & 4.281 & 1.666 & 1.949 & 2.872 & 1.429 & 0.547 \\
\hline & 3 & 5.276 & 0.932 & 1.993 & 4.131 & 1.692 & 1.343 & 2.678 & 1.653 & 0.501 \\
\hline & 4 & 5.352 & 0.903 & 2.009 & 4.029 & 1.676 & 1.873 & 2.761 & 1.410 & 0.507 \\
\hline & 0 & \multicolumn{9}{|l|}{ Initial } \\
\hline & 1 & \multicolumn{9}{|c|}{ Maximization of accessibility } \\
\hline & 2 & \multicolumn{9}{|c|}{ Maximization of accessibility and maximization of acessibility to low-accessibility centers } \\
\hline & 3 & \multicolumn{9}{|c|}{ Maximization of accessibility and maximization of Gini Coefficient } \\
\hline & 4 & \multicolumn{9}{|c|}{ Maximization of accessibility and maximization of Theil Index } \\
\hline
\end{tabular}




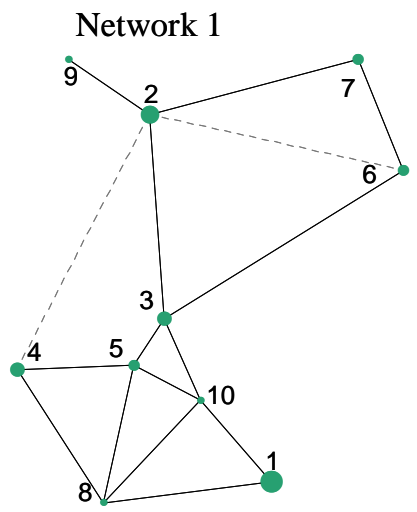

Network 2

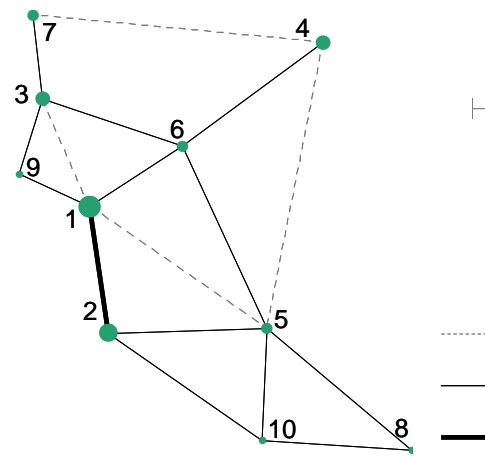

Network 3

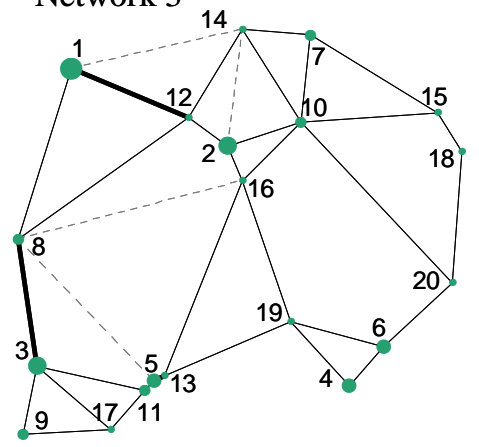

Population Centers

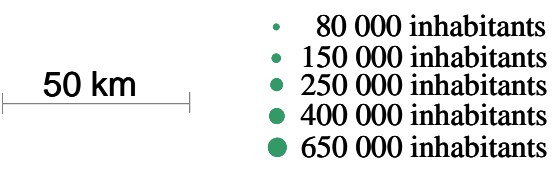

$\begin{array}{lcc}\text { Road Type } & \begin{array}{c}\text { Service flow } \\ \text { (pcu/h) }\end{array} & \begin{array}{c}\text { Free flow } \\ \text { speed }\end{array} \\ \text { Possible Road } & 0 & 0 \mathrm{~km} / \mathrm{h} \\ \text { Slow 2-lane highway } & 1428 & 70 \mathrm{~km} / \mathrm{h} \\ \text { Fast 2-lane highway } & 1869 & 90 \mathrm{~km} / \mathrm{h}\end{array}$

FIGURE 3 - Random networks 

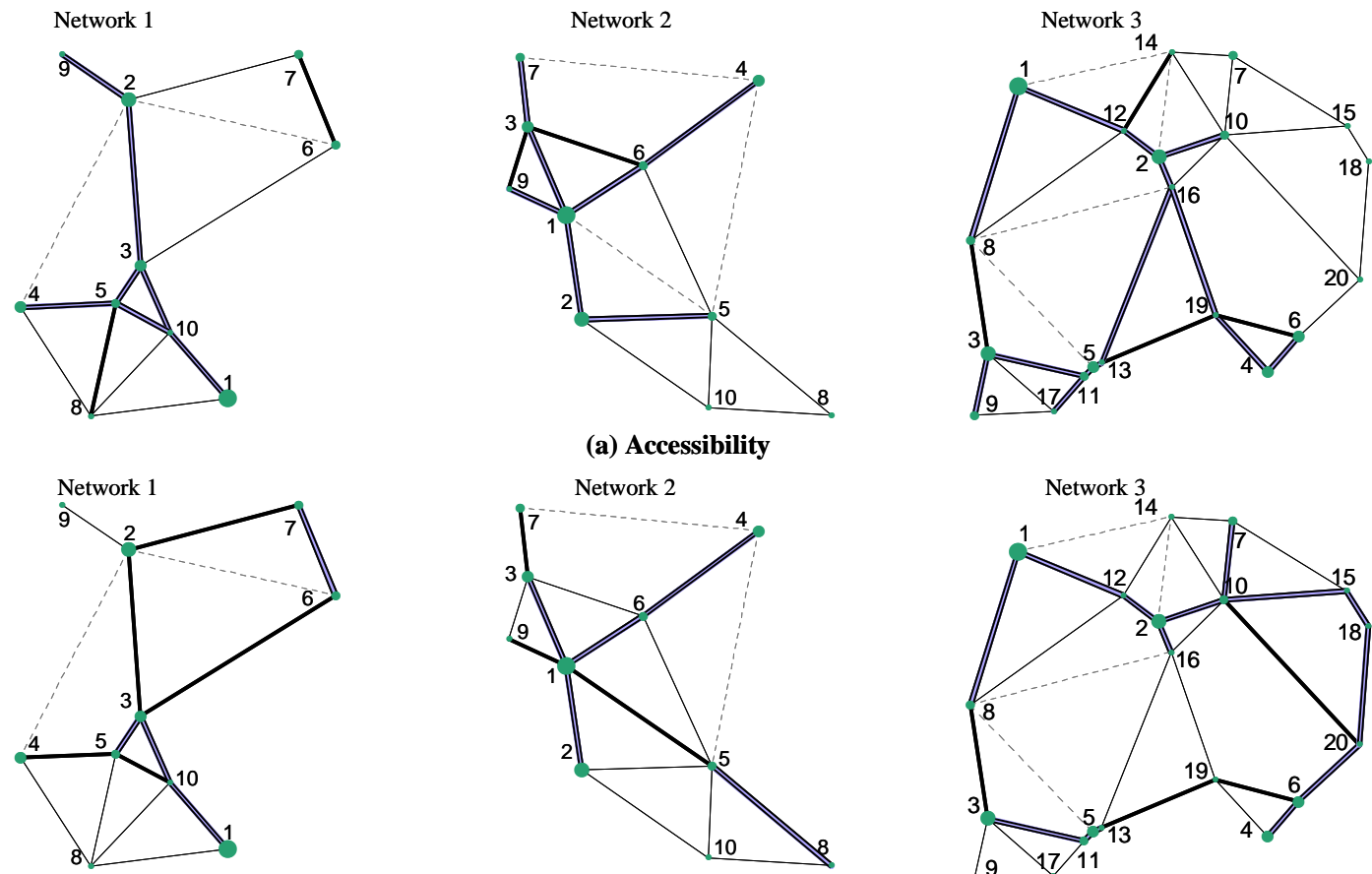

(a) Accessibility
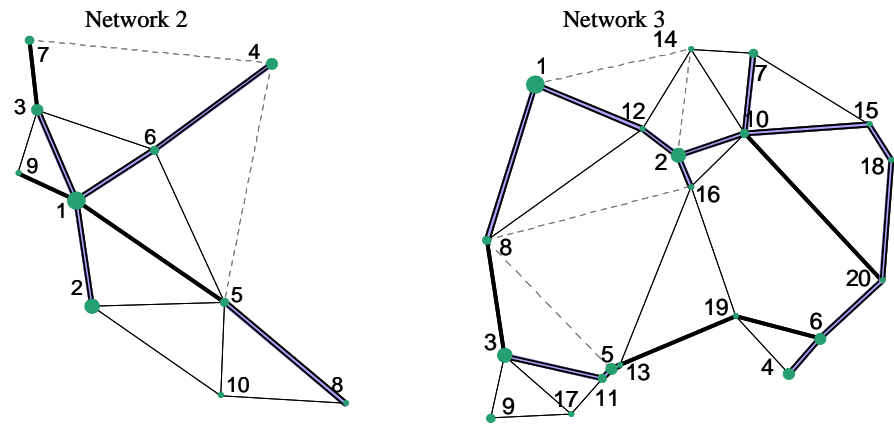

(b) Accessibility and Centers with Lower Accessibility
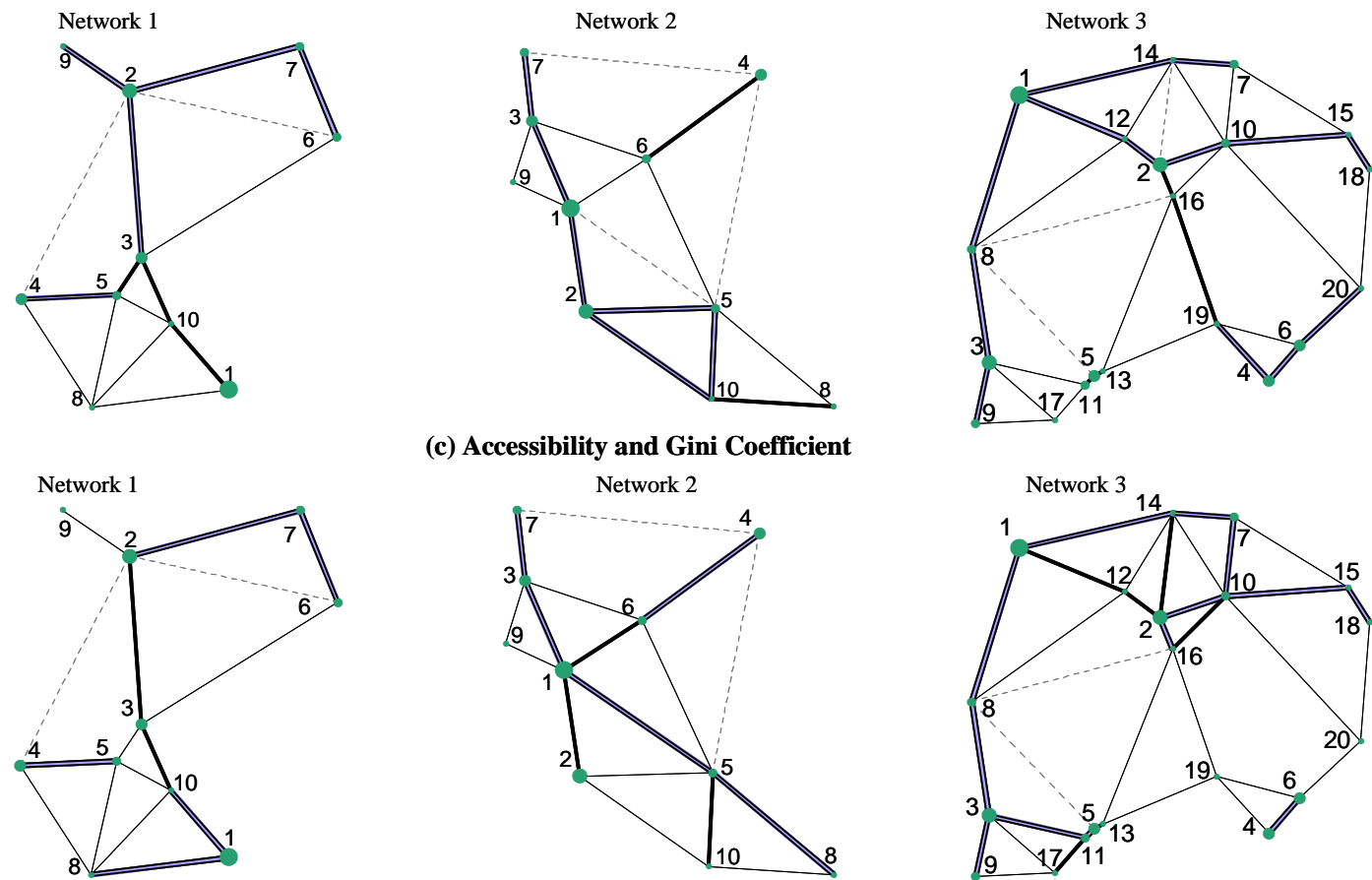

(c) Accessibility and Gini Coefficient
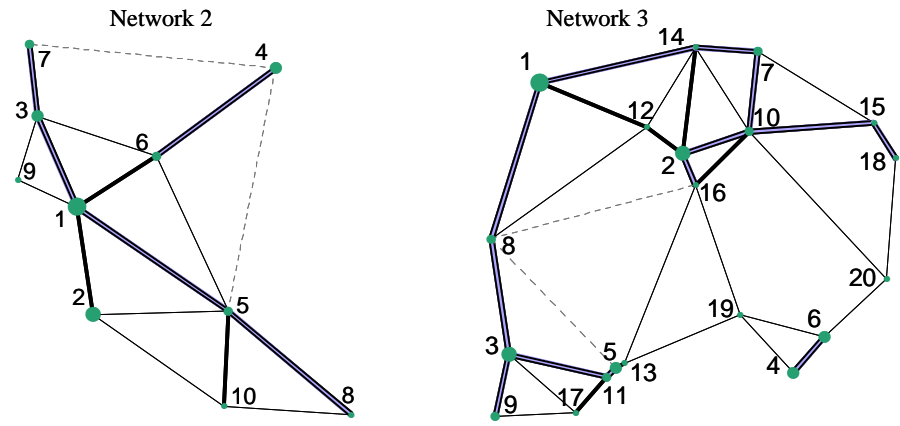

(d) Accessibility and Theil's Inequity Index

Population Centers

- 80000 inhabitants

- 150000 inhabitants

- 250000 inhabitants

- 400000 inhabitants

- 650000 inhabitants

\begin{tabular}{llcc} 
Road Type & $\begin{array}{c}\text { Service flow } \\
(\mathbf{p c u} / \mathrm{h})\end{array}$ & $\begin{array}{c}\text { Free flow } \\
\text { speed }\end{array}$ \\
\hline & Possible Road & 0 & $0 \mathrm{~km} / \mathrm{h}$ \\
- Slow 2-lane highway & 1428 & $70 \mathrm{~km} / \mathrm{h}$ \\
$-\quad$ Fast 2-lane highway & 1869 & $90 \mathrm{~km} / \mathrm{h}$ \\
\hline & 4-lane freeway & 2640 & $120 \mathrm{~km} / \mathrm{h}$
\end{tabular}

FIGURE 4 - Results for the random networks 